\title{
Variation in the Quercetin Content in Different Colored Onions (Allium cepa L.)
}

\author{
Bhimanagouda S. Patil ${ }^{1}$, Leonard M. Pike ${ }^{2}$, and Kil Sun Yoo ${ }^{3}$ \\ Vegetable Improvement Center, Department of Horticultural Sciences, Texas A\&M University, College \\ Station, $T X 77843$ \\ Addition index words. HPLC, cancer, storage
}

\begin{abstract}
The aglycone, or free quercetin, and total quercetin content of 75 cultivars and selections was analyzed by reverse-phase high-performance liquid chromatography. Quercetin glycosides were hydrolyzed into aglycones. Total quercetin content in yellow, pink, and red onions varied from 54 to $286 \mathrm{mg} \cdot \mathrm{kg}^{-1}$ fresh weight in different onion entries grown during 1992. White onions contained trace amounts of total quercetin. Free quercetin content in all the onions was low (< $\left.0.4 \mathrm{mg} \cdot \mathrm{kg}^{-1}\right)$ except in '20272-G' $\left(12.5 \mathrm{mg} \cdot \mathrm{kg}^{-1}\right.$ fresh weight). Bulbs stored at 5 , 24, and 30C and controlled atmosphere (CA) for $0,1,2,3,4$, and 5 months showed a most marked change in total quercetin content at $24 \mathrm{C}$ compared to other treatments, with a rise in mid-storage followed by a drop. Storage at 5 and 30C also demonstrated a similar change. However, total quercetin content did not vary significantly in bulbs stored at CA for 5 months. We conclude that genetic and storage factors affect quercetin content on onions.
\end{abstract}

Given the many positive effects of vegetables on human health, there is increasing interest in foods and beverages that contain quercetin. Onions provide a useful model system to investigate the genetics of plant flavonols (Brown, 1980; Kuhnau, 1976). Another major interest of the food industry in flavonols is their use as therapeutic agents, particularly in cancer. It is surprising that, even though data are available on the presence of quercetin in onion, there has been little research conducted to enhance the content of this compound.

It has been estimated that daily intake of flavonoids in the average American diet amounts to about $1 \mathrm{~g}$, but in some cultures, dietary consumption may be as high as 2 to $3 \mathrm{~g}$ per day (Bier and Nigg, 1992; Kuhnau, 1976). Recently, Hertog et al (1993a) estimated quercetin intake of $16 \mathrm{mg} \cdot \mathrm{day}^{-1}$ in Netherland; however, the total flavonol and flavones is about 5-fold lower than previous findings of Kuhnau (1976). They also indicated that onions contribute about $13 \%$ flavonoid intake in Netherland, of which quercetin made up most of the flavonoid intake $(63 \%)$.

Quercetin has been found to be mutagenic in either the absence or presence of S-9 metabolic activator (Ames, 1983; Bjeldanes and Chang., 1977). Although some evidence of quercetin carcinogenicity has been found (Pamukcu et al., 1980) in Japan, these results could not be confirmed in other studies on various animals (Morino et al., 1982; Saito et al., 1980). It was proposed that in vitro mutagenecity tests, like the Ames test, provide conditions and components required for generating hydroxyl radicals, but such conditions and components usually do not exist under normal physiological conditions (Leighton et al., 1992).

On the other hand, several scientists have undertaken systematic in vivo studies on the biological activity of flavonols. The

Received for publication 8 Mar. 1995. Accepted for publication 6 July 1995. This research was funded by Texas Advanced Technology Program grant and BSP was supported by Rotary Foundation for his doctoral study. We thank Michael J Wargovich for his valuable suggestions during this study and also for his critical comments on this manuscript. We also thank D.L. Madhavi and Barbara Rogers for reviewing this manuscript and for their suggestions. The cost of publishing this paper was defrayed in part by the payment of page charges. Under postal regulations, this paper therefore must be hereby marked advertisement solely to indicate this fact.

${ }^{1}$ Research associate. Present address: Washington State Univ., Irrigated Agricultural Research and Extension Center, Prosser, WA 99350.

${ }^{2}$ Director and professor.

${ }^{3}$ Research assistant professor. anticarcinogenic and antioxidant activity of quercetin has been reviewed (Patil et al., 1995). Quercetin intake is inversely associated with mortality from coronary heart disease (Hertog et al., 1993b).

Breeders and medical researchers are interested in developing onions with higher levels of quercetin. These onions may appeal to the health-conscious consumer. Location and genetic nature affect quercetin content; however, genetic characteristics appear to be predominant in determining the observed variation in quercetin content (Bajaj et al., 1990; Bilyk et al., 1984; Leighton et al., 1992). The need to check for population variation deserves emphasis, since it is often neglected despite of the fact that intraspecific chemical differences in flavonoids have been detected in wellknown species (Harborne, 1986). This study was conducted to determine the variation of aglycone and total quercetin content in representative colored onions and the changes in total quercetin content due to storage conditions at different temperatures.

\section{Materials and Methods}

Sources. Quercetin (3,3',4',5,7 penta hydroxy flavone) was obtained from Sigma Chemical Co., St. Louis.

In 1992, 75 onion entries [37 from the Texas Agricultural Experiment Station, Weslaco; 37 entries grown in two locationsGriffin Brand (GB), McAllen, Texas, and Starr County (ST), Texas, provided by Asgrow Seed Co. (Kalamazoo, Mich.); and a 'Vidalia' onion (unknown cultivar) purchased from Blands Farms, Glenville, Ga.] were obtained.

The onion bulbs were harvested in late April and stored at $5 \mathrm{C}$ for 2 months. The onions were removed from the cooler and kept at room temperature (24C) overnight with air blowing through the boxes. Five bulbs per entry with three replications were evaluated in each experiment.

Sample preparation. A $20 \mathrm{-g}$ sample of tissue from the middle section around the equator of the bulb without dry skin was blended with $80 \mathrm{ml}$ ethanol $(80 \%)$ for $1 \mathrm{~min}$ and filtered through MFS no. 5C filter paper. The filtrate was stored in screw-capped vials at $-20 \mathrm{C}$ until analyzed. A 5-ml aliquot was evaporated to dryness under vacuum at 50C (Buchler evapomix) and resuspended in $1 \mathrm{ml}$ ethanol (80\%). The extracts were filtered through $0.45-\mu$ m nylon 66 filters (Alltech Associates, Deerfield, Ill.), and a $10-\mu 1$ volume of this solution was injected into the high-performance liquid chroma- 
tography (HPLC) system.

Absorption spectra. The absorption spectra (190 to $820 \mathrm{~nm}$ ) of quercetin dissolvedin $80 \%$ ethanol was determinedusing a Hewlett Packard 8452A diode array spectrophotometer. Maximum absorbance of quercetin occurred at $374 \mathrm{~nm}$.

Hydrolysis. Hydrolysis conditions have been optimized (Hertog et al 1992), but, in our study, complete hydrolysis with $99 \%$ recoveries of glycoside peaks were observed with $2 \mathrm{~N} \mathrm{HCl}$ at $80 \mathrm{C}$ for $30 \mathrm{~min}$. The resulting aglycone was quantified by HPLC as described by Markham (1989). Individual fractions of quercetin glycosides were collected based on retention times of respective peaks. Complete hydrolysis of quercetin glycosides yielded aglycone; however, partial hydrolysis of quercetin diglycoside yielded both monoglycoside and aglycone.

Quercetin quantification. Aglycone quantification was performed by using an external standard (free quercetin). Peak areas were normalized to the external standard, and a standard curve was fitted by linear regression (peak area vs. concentration in $\mathrm{mg} \cdot \mathrm{ml}^{-1}$ ). Total quercetin content was calculated by combining total glycosides (from complete hydrolysis to aglycones) and aglycone (standard). Mean recovery for quercetin was $89 \%$ and long-term variatibility of quercetin analysis in the laboratory was low (coefficient of variation $<6 \%$ ). The coefficient of variation for five successive analysis of the same sample was $1 \%$ to $2 \%$ and for five samples from the same onion was $4 \%$ to $9 \%$.

HPLC analysis. The HPLC system consisted of a Perkin-Elmer binary LC pump 250, a Perkin-Elmer LC-600 auto sampler, a PerkinElmer UV/Vis spectrometric detector LC-290, a PV Nelson 900 series interface, a Hewlett-Packard 3394 integrator, and a Bondapak C- 18 column $(250 \times 4.6 \mathrm{~mm}, 10 \mathrm{~m})$ connected to a Bondapak C-18 guard column. The mobile phase consisted of solvent A $(0.5 \%$ orthophasphoric acid in water) and solvent B ( $0.5 \%$ orthophosphoric

Table 1. Variation of aglycone and total quercetin contents among different colored onion entries at different locations (mg.kg ${ }^{-1}$ fresh wt). ${ }^{2}$

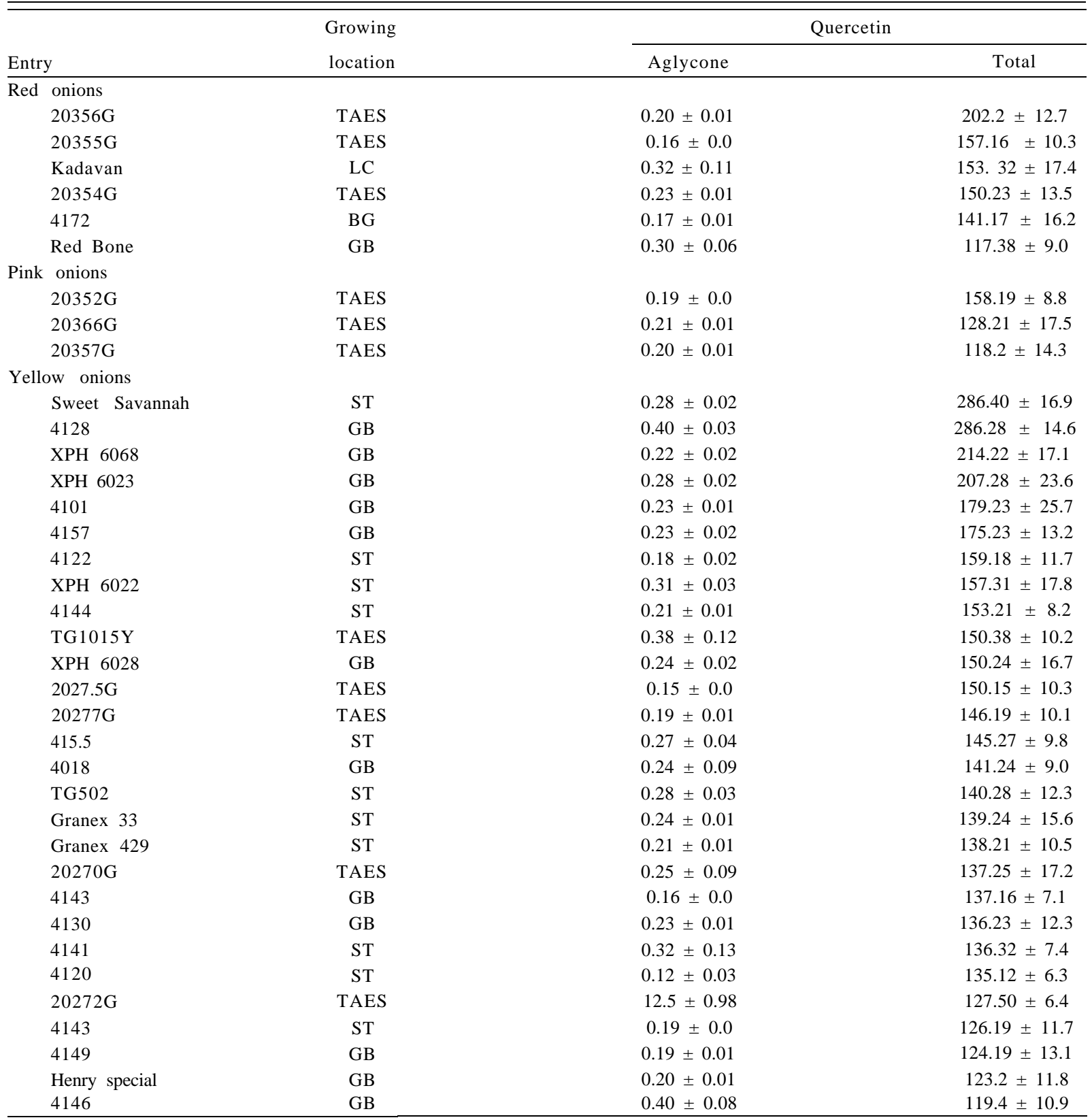


acid in methanol) with the following gradient: (\% B): $10 \mathrm{~mm}, 40 \%$ to $90 \% ; 3.5 \mathrm{~min}, 90 \%$. The flow rate was $1 \mathrm{ml} \cdot \mathrm{min}^{-1}$. Aglycone content was quantified using external standards.

Storage studies. 'Texas Grano 1015Y' bulbs were stored at 5, 24, and $30 \mathrm{C}$ and controlled atmosphere (CA) $\left(99 \% \mathrm{~N}_{2}\right.$ and $1 \% \mathrm{O}_{2}$ at $\left.4.4 \mathrm{C}\right)$ for 5 months. Relative humidity of $50 \%$ to $60 \%$ was maintamed in all storage temperatures. Five bulbs for each temperature with three replications were taken out for extraction every month and total quercetin content was analyzed by reverse-phase HPLC.

Statistical analysis. For variation of quercetin content among different entries, a completely randomized block design was used. Analysis of variance with one-way test was performed with SAS (Cary, N.C.). Storage studies data were analyzed by $4 \times 6$ factorial design with three replications. Mean separations with Duncan's multiple range test were performed at $P=0.05$.

\section{Results and Discussion}

Onions contain quercetin and its glycosides (Bilyk et al, 1984; Herrmann, 1976). In a preliminary experiment, extraction efficiency of several solutions of ethanol and methanol at concentrations of $20 \%, 40 \%, 60 \%, 80 \%$, and $100 \%$ were tested. Quercetin levels were up to $20 \%$ higher at $80 \%$ with ethanol and methanol compared to other solution concentrations (results not shown). Ethanol phase partitioning efficiently extracted flavonols from onions, since the extraction method using methanol yielded the same levels of recovery as determined by absorbance at $374 \mathrm{~nm}$. This specific wavelength corresponds to the maximal absorbance value in extracts from onion. Thus, measuring absorbance at 374 nm provided a useful quantitative estimation of total quercetin content.

Table 1. Continued.

\begin{tabular}{|c|c|c|c|}
\hline \multirow[b]{2}{*}{ Entry } & \multirow{2}{*}{$\begin{array}{l}\text { Growing } \\
\text { location }\end{array}$} & \multicolumn{2}{|c|}{ Quercetin } \\
\hline & & Aglycone & Total \\
\hline 4122 & $\mathrm{~GB}$ & $0.24 \pm 0.02$ & $116.24 \pm 11.5$ \\
\hline $20303 \mathrm{G}$ & TAES & $0.16 \pm 0.0$ & $111.16 \pm 14.3$ \\
\hline $20291 \mathrm{G}$ & TAES & $0.21 \pm 0.06$ & $110.21 \pm 22.1$ \\
\hline $20274 \mathrm{G}$ & TAES & $0.21 \pm 0.01$ & $108.21 \pm 16.2$ \\
\hline 4127 & $\mathrm{ST}$ & $0.16 \pm 0.01$ & $107.16 \pm 13.8$ \\
\hline 4124 & GB & $0.22 \pm 0.01$ & $105.22 \pm 8.5$ \\
\hline 0001 & GB & $0.16 \pm 0.0$ & $100.16 \pm 8.9$ \\
\hline $20288 \mathrm{G}$ & TAES & $0.19 \pm 0.01$ & $98.19 \pm 23.4$ \\
\hline $20276 \mathrm{G}$ & TAES & $0.19 \pm 0.0$ & $96.19 \pm 7.9$ \\
\hline $20280 \mathrm{G}$ & TAES & $0.30 \pm 0.09$ & $95.3 \pm 15.4$ \\
\hline TG502 & GB & $0.22 \pm 0.02$ & $95.22 \pm 11.4$ \\
\hline $20290 \mathrm{G}$ & TAES & $0.16 \pm 0.01$ & $94.16 \pm 11.3$ \\
\hline 4135 & GB & $0.21 \pm 0.05$ & $93.21 \pm 6.9$ \\
\hline $20301 \mathrm{G}$ & TAES & $0.15 \pm 11.3$ & $87.15 \pm 13.9$ \\
\hline Rio Bravo & ST & $0.18 \pm 0.01$ & $86.72 \pm 8.7$ \\
\hline $20253 \mathrm{G}$ & TAES & $0.19 \pm 0.0$ & $85.19 \pm 8.3$ \\
\hline $20330 \mathrm{G}$ & TAES & $0.27 \pm 0.1$ & $81.27 \pm 8.8$ \\
\hline Vidalia & G A & $0.17 \pm 0.0$ & $80.18 \pm 5.2$ \\
\hline $20263 \mathrm{G}$ & TAES & $0.18 \pm 0.01$ & $77.18 \pm 11.6$ \\
\hline $20316 \mathrm{G}$ & TAES & $0.20 \pm 0.03$ & $76.2 \pm 10.2$ \\
\hline $20338 \mathrm{G}$ & TAES & $0.33 \pm 0.05$ & $74.33 \pm 9.1$ \\
\hline $20251 \mathrm{G}$ & TAES & $0.15 \pm 0.0$ & $74.15 \pm 4.6$ \\
\hline $20305 \mathrm{G}$ & TAES & $0.14 \pm 0.0$ & $71.14 \pm 17.3$ \\
\hline 202596 & TAES & $0.19 \pm 0.0$ & $70.19 \pm 9.8$ \\
\hline $20249 \mathrm{G}$ & TAES & $0.16 \pm 0.0$ & $68.16 \pm 7.4$ \\
\hline $20257 \mathrm{G}$ & TAES & $0.16 \pm 0.0$ & $56.16 \pm 15.8$ \\
\hline 4145 & GB & $0.34 \pm 0.03$ & $54.34 \pm 0.02$ \\
\hline \multicolumn{4}{|l|}{ White onions } \\
\hline $20223 \mathrm{G}$ & TAES & $0.56 \pm 0.0$ & $1.41 \pm 0.17$ \\
\hline $20319 \mathrm{G}$ & TAES & $0.26 \pm 0.12$ & $0.91 \pm 0.19$ \\
\hline $20240 \mathrm{G}$ & TAES & $0.14 \pm 0.0$ & $0.56 \pm 0.12$ \\
\hline Contessa & GB & ND & $0.54 \pm 0.05$ \\
\hline $20234 \mathrm{G}$ & TAES & ND & $0.37 \pm 0.07$ \\
\hline 4168 & GB & $\mathrm{ND}$ & $0.37 \pm 0.02$ \\
\hline $20216 \mathrm{G}$ & TAES & ND & $0.36 \pm 0.05$ \\
\hline $20304 \mathrm{G}$ & TAES & $0.13 \pm 0.0$ & $0.41 \pm 0.03$ \\
\hline $20235 \mathrm{G}$ & TAES & ND & $0.27 \pm 0.05$ \\
\hline $20221 \mathrm{G}$ & TAES & ND & $0.26 \pm 0.05$ \\
\hline $20221 \mathrm{G}$ & TAES & $\mathrm{ND}$ & $0.21 \pm 0.01$ \\
\hline
\end{tabular}

${ }^{\bar{Z}}$ Data are given as means of 15 samples \pm SE. Growing locations are ST $=$ Starr County, Texas; GB = Griffin and Brand, McAllen, Texas; TAES = Texas Agricultural Experiment Station, Weslaco; GA = Blands Farms, Glenville, GA; LC = Las Cruces, NM. $\mathrm{ND}=$ not detectable. 
Table 2. Changes in the total quercetin content of 'TG1015Y' onions stored at different temperatures for $5 \mathrm{months}\left(\mathrm{mg} \cdot \mathrm{kg}^{-1}\right.$ fresh wt)'.

\begin{tabular}{lcccc}
\hline \hline & \multicolumn{4}{c}{ Storage temp } \\
\cline { 2 - 5 } Month & $5 \mathrm{C}$ & 24 & 30 & $\mathrm{CA}^{\mathrm{y}}$ \\
\hline 0 & $77.65 \mathrm{a}^{\mathrm{x}} \pm 7.9$ & $78.83 \mathrm{c} \pm 11.7$ & $64.62 \mathrm{ab} \pm 6.1$ & $72.09 \mathrm{a} \pm 9.3$ \\
1 & $54.48 \mathrm{~b} \pm 9.6$ & $121.54 \mathrm{ab} \pm 14.3$ & $75.99 \mathrm{ab} \pm 8.9$ & $66.78 \mathrm{a} \pm 7.3$ \\
2 & $92.87 \mathrm{a} \pm 8.7$ & $96.35 \mathrm{bc} \pm 9.8$ & $86.57 \mathrm{a} \pm 9.7$ & $67.50 \mathrm{a} \pm 6.8$ \\
3 & $52.83 \mathrm{~b} \pm 4.1$ & $140.24 \mathrm{a} \pm 10.2$ & $89.97 \mathrm{a} \pm 17.5$ & $61.45 \mathrm{a} \pm 5.1$ \\
4 & $72.18 \mathrm{ab} \pm 8.3$ & $75.80 \mathrm{c} \pm 9.7$ & $51.05 \mathrm{~b} \pm 5.5$ & $65.24 \mathrm{a} \pm 5.7$ \\
5 & $53.73 \mathrm{~b} \pm \mathbf{5 . 4}$ & $81.50 \mathrm{c} \pm 6.0$ & $68.59 \mathrm{ab} \pm 6.7$ & $63.53 \mathrm{a} \pm 11.3$ \\
\hline
\end{tabular}

${ }^{2}$ Data are given as means of 15 samples + SE.

${ }^{y} \mathrm{CA}=$ controlled atmosphere: $\mathrm{CO}_{2}=99 \%$ and $\mathrm{O}_{2}=1 \%$ at $4.4 \mathrm{C}$.

'Mean separation within columns at $P=0.05$ by Duncan's multiple range test.

Variation of aglycone and total quercetin content among different colored entries. Onions are unusual in the complexity of their flavonol components. The major flavonols in onions are all derivatives of quercetin and monoglycoside, diglycoside, or free aglycone. In all onions studied, spiraeoside was the main quercetincontaining compound present (data not shown). This is consistent with the previous reports (Koeppen and Vander-Spuy, 1961; Leighton et al., 1992).

Breeding onions for improved yield and physiological characters has been well documented. Selection may also affect the quercetin content of plants. It was therefore of interest to investigate a food plant, which had undergone considerable genetic selection, to determine if there are environmental differences that affect quercetin concentration (Herrmann and Woldecke, 1977). Knowledge of genetic differences in quercetin content in onions may be of potential value to breeders if it is confirmed that quercetin confers healthful properties to consumers. Among 75 entries (55 yellow, three pink, six red, and 11 white) analyzed for total quercetin content, the concentration of this flavonol differed significantly, ranging from 0.21 to $286 \mathrm{mg} \cdot \mathrm{kg}^{-1}$ fresh weight (Table 1). The marked variation in total quercetin content was about 1360-fold over entries of all colors including white onions. This variation in total quercetin content among different-colored onions may be genetic in origin (Leighton et al., 1992). The concentration of flavonols is usually $\mathrm{cl} \mathrm{mg} \cdot \mathrm{kg}^{-1}$ fresh weight in root vegetables, even though it might be nearly 1000 -fold higher in leaves. In contrast to root vegetables, onion bulbs (leaf tissue) contain more flavonols (Pierpoint, 1986). It was evident from our data that yellow, red, and pink onions contain higher concentrations of total quercetin, while white onions contain only trace amounts (Table 1). The yellow onion 'Sweet Savannah' had the highest total quercetin content, the red onion '203566' had a medium amount of total quercetin $\left(202 \mathrm{mg} \cdot \mathrm{kg}^{-1}\right)$, while white onions contained only traceamounts. The low amount of total quercetin in white onions was also found by other investigators (Herrmann, 1976; Leighton et al., 1992).

The high quercetin content reported by Kuhnau (1976) could be due to analyses of whole onions as opposed to edible parts, as in this study. Further, supporting evidences for significant differences between edible vs. nonedible onion parts have been reported elsewhere (Patil and Pike, 1995). The variation in total quercetin content among yellow, pink, and red onions, was 5-fold. It was clear that yellow onions contained more total quercetin than red onions. This conflicts with the results of Kiviranta et al (1988). Although previous studies have indicated that color might be due to the presence of quercetin (Bajaj et al., 1990; Laul et al., 1984), our results demonstrated that other factors are involved in determining high quercetin. In contrast, the reports of Bajaj et al. (1990) suggest that there could be higher quercetin content in red onions than white onions if we consider only white and red onions. Although pink onions are uncommon in the market, all three pink genotypes from the Texas Agricultural Experiment Station breeding program contained moderate amounts of total quercetin. Since various glycosides of the same aglycone do not alter flower color in geranium (Asen, 1982) the variation in total quercetin content of yellow and red onions might-be due to genetic factors other than pigments.

Evidence suggests that aglycone has greater pharmacological activity than its glycosides. Therefore, onions bred for high aglycone content may have more health benefits. Interestingly enough, the yellow onion '20272-G' had high aglycone content (12.50 $\mathrm{mg} \cdot \mathrm{kg}^{-1}$ ), while no other entry had $>0.6 \mathrm{mg} \cdot \mathrm{kg}^{-1}$, irrespective of the color. High aglycone content in '20272-G' may be under genetic control rather than environmental influence since all entries were grown in the same field and analyzed similarly.

Variation of total quercetin content due to storage conditions. Little data on storage effect on changes in quercetin content has been published. Changes in total quercetin content in 'TG1015Y' stored at three temperatures $(5,24$, and $30 \mathrm{C})$ and CA for 5 months is presented in Table 2. Total quercetin content in bulbs stored at 24C showed significant $(\mathrm{P}=0.05)$ changes during 1,2 , and 3 months, while quercetin content was similar at 0,4 , and 5 months. We observed bulb sprouting in all storage conditions except CA storage. The nonconsistent pattern of quercetin content in storage conditions $(5,24$, and 30C) may be due to bulb sprouting. CA storage did not produce significant changes in quercetin content during storage. The nonsignificant differences in quercetin content for 5 months in CA storage could be due to the fact that internal decay of bulbs was not observed at 4.4C (Adamicki and Kepka, 1974). Since our samples presented in Table 1 were analyzed within 2 months of storage at $5 \mathrm{C}$, our data could have been only slightly influenced by storage effects on total quercetin content. However, diglycoside content did not show any increasing trend at the expense of the monoglycosides during any of our storage conditions, which conflicts with previous results (Starke and Herrman, 1976).

Knowledge of differences in quercetin content among different onion entries is a basic requirement for breeders who are dealing with onions for health benefits. In summary, our results indicated that red, pink, and yellow onions had more quercetin than white onions. However, color may not be the only criterion affecting total quercetin content, suggesting that there is the potential to breed for onions with high quercetin content independent of color.

Previous researchers assumed that quercetin might be mutagenic and toxic and reported that varietal differences in quercetin could be a basis for breeding for reduced quercetin content (Bilyk et al., 1984). Considering the biological effects of quercetin, it is generally unclear whether quercetin is beneficial or harmful to humans. 


\section{Literature Cited}

Adamicki, F. and A.K. Kepka. 1974. Storage of onions in controlled atmosphere. Acta Hort. 3853-57.

Ames, B.N. 1983. Dietary carcinogenesis and anticarcinogenesis. Science 221:1256-1264.

Asen, S. 1982. Identification of flavonoid chemical markers in roses and their high pressure liquid chromatographic resolution and quantitation for genotype identification. J. Amer. Soc. Hort. Sci. 107:744-750.

Bajaj, K.L., G. Kaur, and M.L. Chadha. 1990. Varietal variations in some important chemical constituents of onion (Allium cepa L.). Crop Sci. 30:391-395.

Bier, R.C. and H.N. Nigg. 1992. Natural toxicants in foods, p. 247-367. In: H.N. Nigg and D. Seigler (eds.). Phytochemical resources for medicine and agriculture. Plenum Press, New York.

Bilyk, A., P.L. Cooper, and G.M. Sapers. 1984. Varietal differences in distribution of quercetin and kaempferol in onion (Allium cepa L.) tissue. J. Agr. Food Chem. 32:274-276.

Bjeldanes, L.F. and G.W. Chang. 1977. Mutagenic activity of quercetin and related compounds. Science 197:577-578.

Brown, J.P. 1980. A review of genetic effects of naturally occurring flavonoids, antraquinones and related compounds. Mutation Res. 75:243277.

Harborne, J.B. 1986. Nature, distribution and functions of plant flavonoids. Prog. Clin. Biol. Res. 213:15-24.

Herrmann, K. 1976. Flavonols and flavones in food plants: A review. J. Food Technol. 11:433-448.

Herrmarnn. K. and M. Woldecke. 1977. The flavonol content of peas as influenced by variety and light and a note on the flavonol content of broad beans. J. Sci. Food Agr. 28:365-368.

Hertog, M.G.L., P.C.H. Hollman, and D.P. Venema. 1992. Optimization of quantitative HPLC determination of potentially anticarcinogenic flavonoids in vegetables and fruits. J. Agr. Food Chem. 40:1591-1598.

Hertog, M.G.L., J.M. Feskens, P.C.H. Hollman, M.B. Katan, and D. Krombout. 1993a. Intake of potentially anticarcinogenic flavonoids and their determinants in adults in the Netherlands. Nutr. Cancer 20(1):21-29.

Hertog, M.G.L., J.M. Feskens, P.C. H. Hollman, M.B. Katan, and D. Kromhout. 1993b. Dietary antioxidant flavonoids and risk of coronary heart disease: The Zutphen elderly study. Lancet 342:1007-1011
Kiviranta, J., K. Huovinen, and P. Hiltunen. 1988. Variation of phenolic substances in onion. Acta Pharm. Fenn. 91:67-72.

Koeppen, B.H. and J.E. Vander-spuy. 1961. Microbial hydrolysis of quercetin glycosides from the inner rings of the onion (Allium cepa $\mathrm{L}$.). S. Afr. J. Agr. Sci. 4(4):557-563.

Kuhnau, J. 1976. The flavonoids. A class of semi-essential food components: Their role in human nutrition. World Rev. Nutr. Diet. 24: 117 191.

Laul, M.S., S.D. Bhalenao, G.V. Muhmoley, G.R. Shah, and VS. Palal. 1984. Curing and storage of Nasik red onions (Allium cepa L.). Indian Food Packer 38(6):30-39.

Leighton, T., C. Glinther, L. Fluss, W.K. Harte, J. Cansado, and V. Notario. 1992. Molecular characterization of quercetin and quercetin glycosides in Allium vegetables: Their effects on cell transformation, $\mathrm{p}$. 221-238. In: Huang, M.T., C.Y. Lee, and C.T. Ho (eds.). Phenolic compounds in food and their effects on health. Amer. Chem. Soc., New $\mathrm{Y} \quad \mathrm{o} \quad \mathrm{r} \quad \mathrm{k}$.

Markham, K.D. 1989. Flavones, flavonols and their glycosides, p. 197235. In: J.B. Harborne (ed.). Methods in plant chemistry. vol. 1. Plant phenolics. Academic Press, New York.

Morino, K., N. Matsukura, T. Kawachi, H. Ohgaki, T. Sugimura, and I. Hirono. 1982. Carcinogenicity test of quercetin and rutin in golden hamsters by oral administration. Carcinogenesis 3:9-97.

Pamukcu, A.M., S. Yalciner, J.F. Hatcher, and G.T. Bryan. 1980. Quercetin, a rat intestinal and bladder carcinogen present in brakern fern (Pteridium aquilinum). Cancer Res. 40:3468-3472.

Patil, B.S. and L.M. Pike. 1995. Distribution ofpotentially anticarcinogenic quercetin content in different rings of various colored onion (Allium cepa L.) cultivars. J. Hort. Sci. 70 (4):643-650.

Patil, B.S. , L.M. Pike, and B.K. Hamilton. 1995. Changes in quercetin concentration in onion (Allium cepa L.) owing to location, growth stage and soil type. New Phytol. 130(3):349-355.

Pierpoint, W.S. 1986. Flavonoid in the human diet. Prog. Clin. Biol. Res. 213:125-140.

Saito, D.D., A. Shirai, T. Matsushima, T. Sugimura, and I. Hirano. 1980. Test of carcinogenicity of quercetin, a widely distributed mutagen in food. Teratog. Carcinog. Mutagen. 1:213-221.

Starke, H. and H. Herrmann. 1976. Flavonole und flavone der gem usearten. Z Lebenson Unters. Forsch. 161:137-141. 